UNIVERSIDADE DE BRASÍLIA - UnB

FACULDADE DE ECONOMIA, ADMINISTRAÇÃO, CONTABILIDADE E CIÊNCIA DA INFORMAÇÃO E DOCUMENTAÇÃO - FACE

FELIPE MELO BARJUD

\author{
DIRETRIZES PARA A IMPLANTAÇÃO \\ DO SISTEMA DE CUSTOS ABC \\ PARA EMPRESAS PÚBLICAS \\ PRESTADORAS DE SERVIÇOS
}

Brasília - DF

2009 
FELIPE MELO BARJUD

\title{
DIRETRIZES PARA IMPLANTAÇÃO \\ DO SISTEMA DE CUSTOS ABC PARA EMPRESAS PÚBLICAS PRESTADORAS DE SERVIÇOS
}

\begin{abstract}
Monografia apresentada ao Programa de PósGraduação em Administração (PPGA) da Faculdade de Economia, Administração, Contabilidade e Ciência da Informação e Documentação (FACE), da Universidade de Brasília, como requisito parcial à obtenção do grau de Especialista em Orçamento e Finanças.
\end{abstract}

Orientador: FRANCISCO GLAUBER LIMA MOTA

Brasília - DF 


\section{AGRADECIMENTOS}

Agradeço a Deus por me mostrar constantemente a sua presença, ao SERPRO pela oportunidade disponibilizada e a minha esposa Andréia Barjud e aos meus filhos Davi e Vitor por compreenderem e aceitarem a minha ausência, por saberem que este esforço faz parte de meu crescimento profissional. Agradeço também ao professor Francisco Glauber por orientar-me de forma coerente e objetiva no desenvolvimento desta monografia. 


\section{RESUMO}

Motivado pela crescente evolução participativa do Setor de Serviços no Produto Interno Bruto brasileiro e sabendo que boa parte destes serviços são executados por empresas públicas nacionais, este trabalho, desenvolvido através de pesquisas bibliográficas, pesquisas documentais e experiências adquirida ao longo da carreira profissional no SERPRO (Serviço Federal de Processamento de Dados), teve por objetivo apresentar os conceitos e diretrizes para uma boa implantação e gerenciamento de um sistema de custeio baseado em atividades (ABC) em empresas públicas prestadoras de serviços. A metodologia de custeio apresentada evidencia a eficiência no consumo de recursos, destacando assuntos relevantes como a vinculação da Contabilidade Gerencial e a Contabilidade de Custos, onde neste último foram demonstradas: a importância da Gestão Estratégica de Custo (Gestão Competitiva ou Social); a importância do estabelecimento de Custos Padrões focado no Controle Empresarial; a importância do Controle da Ociosidade (Desperdícios) e as tão debatidas metodologias de custeio: Metodologia de Centro de Custo, Metodologia de Custeio Baseado em Atividades (ABC) e a Metodologia de Custo Total de Propriedade (TCO), sendo esta última voltada especificamente a empresas prestadoras de serviços de Tecnologia da Informação desenvolvedoras de softwares. Com a conclusão do trabalho foram apresentadas como resultados, considerações e diretrizes necessárias para o sucesso do plano de implantação da metodologia de custeio $A B C$ :

Diretrizes: conhecimento da estratégia empresarial a ser seguida (Competitiva ou Social), considerar aspectos gerenciais (Operacional, Tático e Estratégico), identificação dos processos produtivos da empresa com suas respectivas estruturas de custos e ter bem definida a cadeia de alocação dos custos (Recursos, Atividades e Objetos de Custos).

Considerações: estabelecer uma previsão de custos para o controle gerencial (Custo Padrão), atenção aos elevados custos de pessoal nas empresas públicas 
prestadoras de serviços, apoio empresarial ao nível de diretoria, comprometimento ao nível operacional e um sistema de informação adequado à metodologia.

Palavras Chaves: Empresa Pública Prestadora de Serviços, Contabilidade de Custos e Metodologia de Custeio Baseado em Atividades, Diretrizes para implantação da metodologia $A B C$. 


\section{LISTA DE FIGURAS}

Figura 1 - Sistema de Informação Contábil................................................. 18

Figura 2 - Fatores Determinantes da Competitividade da Empresa.............. 20

Figura 3 - Matriz de Custos.................................................................. 23

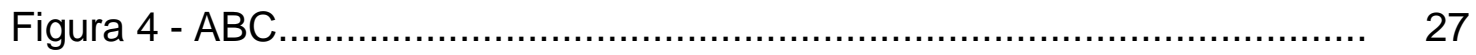

Figura 5 - Detalhamento de um processo................................................ 29

Figura 6 - Modelo Geral de Análise de Variações - Custos Variáveis........... 32

Figura 7 - Estratégias.......................................................................... $\quad 39$ 


\section{LISTA DE GRÁFICOS}

Gráfico 1 - Participação percentual do Setor de Serviços em relação ao

Produto Interno Bruto a preço corrente (2005-2008) 


\section{LISTA DE TABELAS}

Tabela 1 - Valores a preços correntes........................................................ 14

Tabela 2 - Encargos Sociais............................................................... 40 


\section{SUMÁRIO}

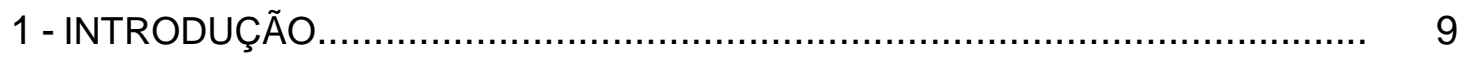

1.1 - Formulação do Problema de Pesquisa.................................................. 9

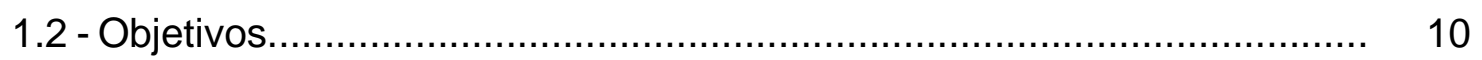

1.2.1 - Objetivo Geral.............................................................. 10

1.2 .2 - Objetivo Específico................................................................ 10

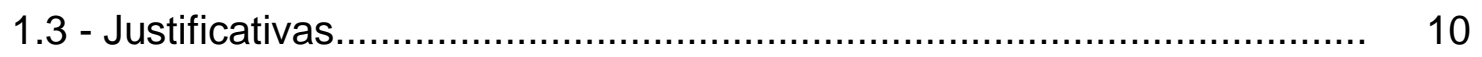

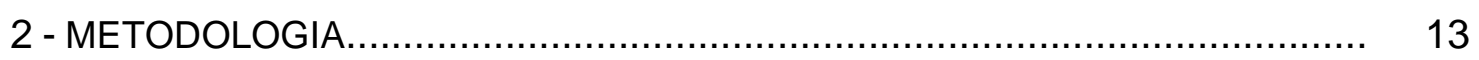

3 - REFERENCIAL TEÓRICO...................................................... 14

3.1 - Contabilidade Gerencial............................................................ 16

3.2 - Contabilidade de Custos.............................................................. 18

3.3 - Gestão Estratégica de Custos........................................................... 19

3.4 - Metodologia de Custeio................................................................ 21

3.4.1 - Metodologia dos Centros de Custos.............................................. 21

3.4.2 - Metodologia de Custeio Baseado em Atividades (ABC).................... 24

3.4.3 - Total Cost of Ownership (TCO).................................................. $\quad 29$

3.5 - Custo para Controle e Custos Padrões............................................... $\quad 30$

3.6 - Ociosidade e Desperdício.................................................................. 33

4 - DESENVOLVIMENTO..................................................................... 35

4.1 - Diretrizes para implantação de um sistema de custeio ABC em 35 empresas públicas prestadoras de serviços..............................................

4.1.1 - Considerações a Implantação do Modelo.......................................... 39

4.2 - Sistema de Custeio e Previsão Orçamentária........................................ 42

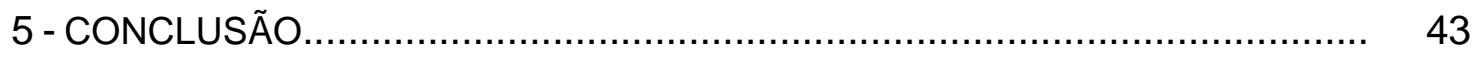

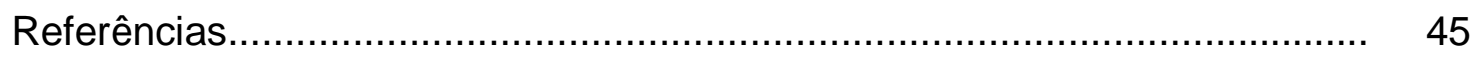

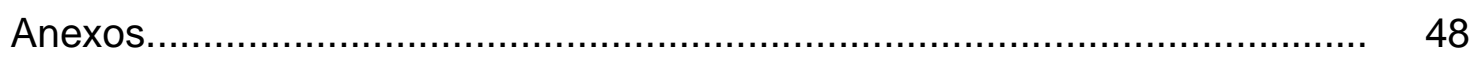




\section{INTRODUÇÃO}

Nos últimos anos, vem sendo destacada a necessidade de se introduzir mecanismos competitivos na administração pública de modo a melhorar seu desempenho. Entretanto, a introdução desses mecanismos não pode impregnar todas as atividades governamentais, pois o sucesso de novos modelos de gestão da administração pública será determinado exatamente pela integração adequada das estratégias competitivas e cooperativas. Uma das diversas maneiras de se avaliar a necessidade e o resultado de implantação de uma estratégia é através da análise de indicadores de gerenciamento de custos.

Este trabalho tem o objetivo de apresentar, dentro do campo da contabilidade gerencial - parte integrante de um processo de gestão, as diretrizes necessárias para implantação de um sistema de medição e gerenciamento de custos em empresas públicas prestadoras de serviços. Entre os conceitos básicos que foram apresentados estão: a identificação dos processos produtivos para determinação do catálogo de atividades de acordo com as características de um sistema de custeio baseado em atividades, a definição de um plano de contas como forma de detalhar as etapas do gerenciamento, apresentar a importância de uma gestão estratégica de custos como forma de subsidiar decisões, identificar e exemplificar uma estrutura de cadeia de valor ou alocação de produção e, finalmente, a apresentação da importância do controle da ociosidade ou desperdício, já que, as empresas prestadoras de serviços são impossibilitadas de formarem estoques, onde toda a disponibilidade da produção não utilizada passa a ser perda ou desperdício.

\section{1 - Formulação do problema de pesquisa}

Quais as diretrizes necessárias para prover, para as empresas públicas prestadoras de serviços, um sistema de apuração e gerenciamento de custos focado na análise de resultados, na mensuração da eficiência dos gastos públicos e na competitividade de mercado? 


\section{2 - Objetivos}

\subsection{1 - Objetivo geral}

O objetivo do trabalho é apresentar conceitos e diretrizes necessárias à implantação de um sistema de apuração e gerenciamento de custos capaz de evidenciar a eficiência na utilização de recursos em empresas prestadoras de serviços.

\subsection{2 - Objetivos específicos}

- Demonstrar, conforme referencial teórico, os critérios de implantação da metodologia de custeio baseado em atividades para empresas públicas prestadoras de serviços.

- Analisar, de acordo com a metodologia de custeio identificada, a cadeia de alocação dos custos e sua respectiva eficiência alocativa.

- Apresentar a necessidade de gerenciamento dos custos de ociosidade produtiva que são muito comuns em empresas prestadoras de serviços que, por ter característica própria, não geram estoques e sim perdas.

\section{3 - Justificativa}

No final da década de 80 e início da década de 90 o Estado passou a ter uma maior exposição da economia nacional à competição internacional, com isso foi forçado a reorientar sua política econômica e, em especial, conter as despesas. Dada a dificuldade política de implantação de uma medida fiscal expansionista, especialmente em relação à tributação direta, as palavras de ordem passaram a ser cortar gastos. $\mathrm{O}$ governo muitas vezes teve a noção de quanto precisaria cortar as despesas em decorrência do equilíbrio macroeconômico, porém não soube ao certo como e onde deveria cortar, ou seja, o governo teve dificuldade de providenciar cortes seletivos de gastos de modo a não comprometer ainda mais o desempenho da administração pública. Assim, a redução de gastos com melhoria de desempenho tornou-se uma 
alternativa impraticável, ainda que necessária. Segundo Alonso (1999, p.38), ao comprometer a qualidade dos serviços públicos, os cortes de despesa comprometem, por extensão, a competitividade da economia nacional, dado o caráter sistêmico da competitividade.

Outra justificativa a ser acrescida, para o estudo de gerenciamento de custos em empresas prestadoras de serviços públicos, é o fato da apuração e da divulgação de indicadores de resultado e de custos servirem de guia para a mudança organizacional e de incentivo para os agentes de mudança, além de evidenciar problemas de medidas de desempenho organizacional, como:

- viabilizar a redução de custos à melhoria da qualidade dos serviços prestados;

- instrumentalizar o combate ao desperdício;

- gerar indicadores de avaliação de impacto efetivo das decisões já tomadas pela empresa e;

- falta de subsídio de avaliação de planos de reestruturação de processos produtivos e melhoria de gestão.

Segundo o Boletim IOB de Contabilidade (fascículo 33/2006), o objetivo de estudar custos em uma empresa de serviços, é justificável pelos seguintes itens:

- conhecer o resultado obtido pela empresa através do gerenciamento efetivo de custos;

- controlar, através de indicadores de custos, a eficiência da organização e de cada um dos seus centros de responsabilidades e;

- tomar decisões que facilitem a manutenção e a melhoria contínua da posição competitiva da empresa.

O modelo de gestão tradicional do setor público prioriza o controle dos recursos e dos procedimentos formais, e não os resultados, o desempenho e a eficiência. 
Portanto, não há dúvidas de que discutir este tema - gerenciamento de custos no serviço público - além de ser necessário, tem importância crescente para a administração pública. 


\section{2 - METODOLOGIA}

São apresentado neste capítulo os métodos e as técnicas de pesquisa utilizadas para o desenvolvimento do trabalho. A metodologia também pode ser vista como uma maneira de se conduzir um processo de pesquisa (conjunto de regras). É a explicação minuciosa e exata de toda ação desenvolvida no trabalho de pesquisa empírica, considerando o tipo de pesquisa adotado e a amostra selecionada.

Segundo Silva e Menezes (2001, p.9) o sucesso de uma pesquisa depende dos procedimentos seguidos, do envolvimento com a pesquisa e da habilidade em escolher o caminho para atingir os objetivos da pesquisa.

Portanto, foram utilizados, para o desenvolvimento deste trabalho, os seguintes métodos:

- A pesquisa bibliográfica em materiais publicados sobre o sistema ABC (ActivityBased Costing) e sobre a implantação deste sistema em empresas prestadoras de serviços.

- Pesquisa documental em registros legais e publicações próprias de empresas públicas e privadas que já implantaram o sistema $A B C$ de Custeio.

- Experiência adquirida ao longo da carreira profissional com a realização de trabalhos relacionados como o tema no SERPRO - Serviço Federal de Processamento de Dados, bem como em participação em Eventos (Congressos, Palestras, etc) e treinamentos.

Buscou-se neste trabalho manter uma relação dinâmica (aderência) da teoria com o mundo real, expondo as necessidades, dificuldades e ganhos com a implantação do modelo de custeio baseado em atividades. 


\section{REFERENCIAL TEÓRICO}

Melhorar a eficiência e reestruturar a empresa tornaram-se metas comuns no atual ambiente de negócios e, com isso, as informações de custos passam a ser cada vez mais relevantes.

Neste capítulo, são apresentados ao leitor a importância da contabilidade gerencial e sua vinculação com a contabilidade de custos, os meios de busca da eficiência produtiva através da gestão estratégica de custos, as vantagens do sistema de custeio baseado em atividades para empresas prestadoras de serviços públicos e finalmente as diretrizes para implantação de uma sistemática de custeio baseado em atividades.

No Brasil, os serviços estão no centro da atividade econômica. De acordo com o Sistema IBGE de Recuperação Automática - SIDRA (IBGE, 2008), 64,12\% (Tabela 1) do Produto Interno Bruto a preço corrente é gerado pelo denominado setor de Serviços.

Tabela 1: Valores a preços correntes

Brasil - Milhões de Reais

\begin{tabular}{c|c|c}
\hline SETORES E SUBSETORES & $\begin{array}{c}\mathbf{2 0 0 8} \\
\text { JUL-SET }\end{array}$ & $\%$ \\
\hline Agropecuária - total & 37.330 & $5,91 \%$ \\
\hline Indústria - total & 189.255 & $29,97 \%$ \\
\hline Serviços - total & 404.973 & $64,12 \%$ \\
\hline PIB a preços corrente & $\mathbf{6 3 1 . 5 5 8}$ & - \\
\hline
\end{tabular}

Fonte: IBGE (2008)

A tabela acima foi extraída da série apresentada no Anexo $A$, que demonstra os valores a preço corrente e a preço de mercado referente aos quatro últimos trimestres.

Já o Anexo B apresenta a evolução da composição do Produto Interno Bruto nos três setores da economia: Primário, Secundário e Terciário. Desta tabela foi extraída o gráfico 1 que representa a participação percentual do setor de Serviços em relação ao Produto Interno Bruto a preço corrente para os trimestres dos anos de 2005 a 2008, 
comprovando que os serviços têm contribuído com a maior parcela da Produção Interna.

Gráfico 1: Participação percentual do Setor de Serviços em relação ao Produto Interno Bruto a preço corrente (2005-2008)

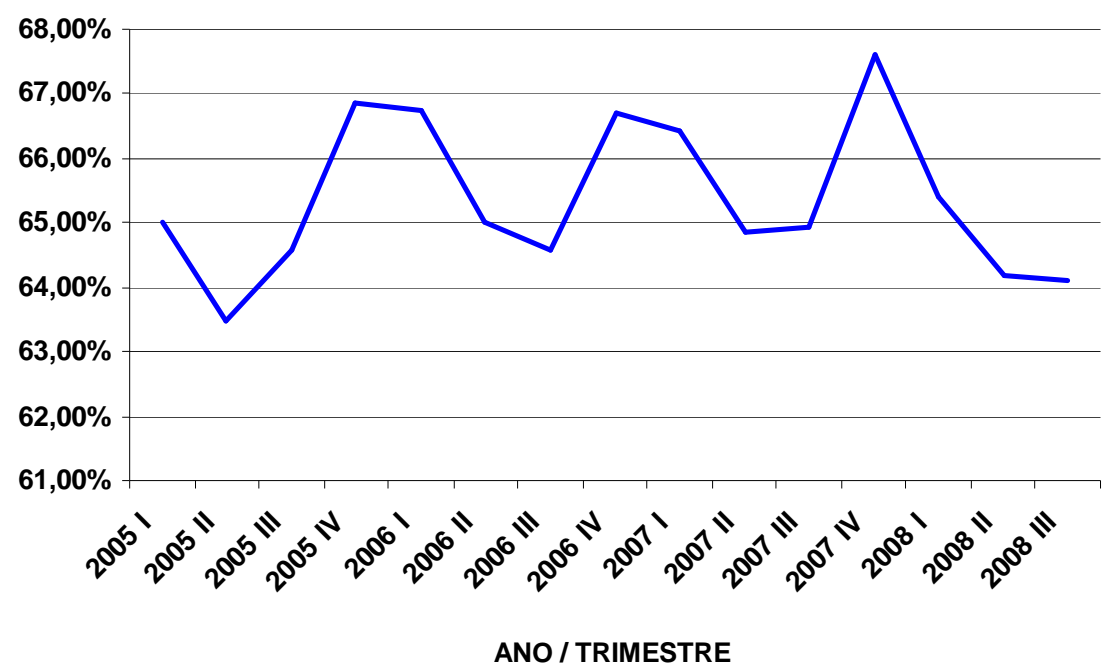

Fonte: IBGE (2008)

Diante dessas informações ficam claras as percepções das empresas prestadoras de serviços e de seus respectivos gestores em controlar os custos. Albrecht (2000, p.6) faz uma consideração importante sobre o tema: "Um dos indícios da revolução dos serviços é o fato de que os analistas de empresas estão começando a tratar as organizações de prestação de serviços como uma categoria empresarial claramente diferenciada, merecedora de acompanhamento estatístico".

Portanto, diante dos objetivos apresentados, é necessária a identificação das diretrizes de implantação de um sistema de custo capaz de organizar informações e direcionar os custos aos diversos componentes da cadeia de produção, proporcionado tanto uma apuração confiável como um gerenciamento efetivo. Porém, antes iniciar propriamente o trabalho é importância alertar, para o bom entendimento do trabalho, que empresas prestadoras de serviços possuem particularidades na operacionalização 
da produção que são extremamente relevantes para a administração de custos, quais sejam:

- Intangibilidade: os serviços são abstratos, são idéias, são conceitos, são códigos e são, sobretudo, de difícil padronização.

- Necessidade de presença do cliente: é o cliente que inicia o serviço através de sua solicitação, dizendo o que quer, para quando quer e como quer. Nas organizações de serviço o elemento humano é fundamental para a eficiência das operações e a mão-de-obra é, freqüentemente, o recurso determinante da eficácia da organização.

- Produção e consumo simultâneos de serviços: geralmente, não há uma etapa entre a produção de um serviço e seu consumo por parte do cliente. Os serviços são criados e consumidos simultaneamente e, portanto, não podem ser estocados. Como os serviços não podem ser estocados a capacidade produtiva colocada disponível e que não seja utilizada (pela falta de demanda ou erro na previsão do serviço), será perdida para sempre.

\section{1 - Contabilidade Gerencial}

De acordo com Padoveze (2004, p.37), a Contabilidade Gerencial é o processo de identificação, mensuração, acumulação, análise, preparação, interpretação e comunicação de informações financeiras utilizadas pela administração para planejamento, avaliação e controle dentro de uma organização, além de assegurar e contabilizar o uso apropriado de seus recursos.

Kaplan, et al. (2000, p.36) afirmam que a "contabilidade é o processo de produzir informações operacionais e financeiras para funcionários e administradores. O processo deve ser direcionado pelas necessidades informacionais dos indivíduos internos da empresa, bem como orientar suas decisões de investimentos".

A Contabilidade Gerencial adiciona valor distintivamente pela investigação contínua sobre a efetividade da utilização dos recursos pelas organizações na criação de valor para os acionistas, clientes e outros credores, mantendo, simultaneamente, 
essa relação com o fornecimento de informações para os administradores - aqueles que estão dentro da organização e que são responsáveis pela direção e controle de suas operações.

Neste contexto, há, de um lado, os administradores que são supridos de informações a respeito das condições econômicas da empresa como: custos e lucratividade de produtos e serviços, manutenção de clientes e das atividades da empresa. Além disso, a informação mede o desempenho econômico de unidades operacionais descentralizadas ligando a estratégia da empresa à execução da estratégia individual de cada unidade operacional. Do outro, os acionistas, que têm o objetivo de criação de valor, isto é, a geração de lucro empresarial transferido aos proprietários e monitorado adequadamente por meio de adoção da mensuração do lucro econômico com o apoio de atividades operacionais de informações contábeis gerenciais.

Segundo Padoveze (2004, p.39) a Contabilidade Gerencial apresenta as seguintes características específicas:

- Possui um objetivo especial de facilitar o planejamento, controle, avaliação de desempenho e tomada de decisão internamente.

- Vincula-se ao orçamento, pratica a contabilidade por responsabilidade e desempenho e realiza uma análise de custos focada na tomada de decisão.

- Utilização pesada de outras disciplinas como economia, finanças, estatística, pesquisa operacional e comportamento organizacional.

- Contabilidade orientada para o futuro de forma a facilitar o planejamento, controle e avaliação de desempenho antes do fato (para impor metas), acoplada com uma orientação histórica para avaliar os resultados reais (para o controle posterior ao fato).

O mesmo autor (PADOVEZE, 2004, p.44 e p.309) vai mais além quando afirma que, dentro do Gerenciamento Contábil específico, os temas tratados, na sua maioria, na contabilidade gerencial são oriundos da Contabilidade de Custos que tem tanto a vantagem de provocar a aproximação da administração da empresa com as unidades 
fabris, como dispor de uma estrutura de informação capaz de prover o planejamento e o controle. A contabilidade de custo é tratada pelo autor como um subsistema da contabilidade gerencial, capaz de atender às exigências fiscais de integração e coordenação com a contabilidade financeira, conforme ilustrado na Figura 1.

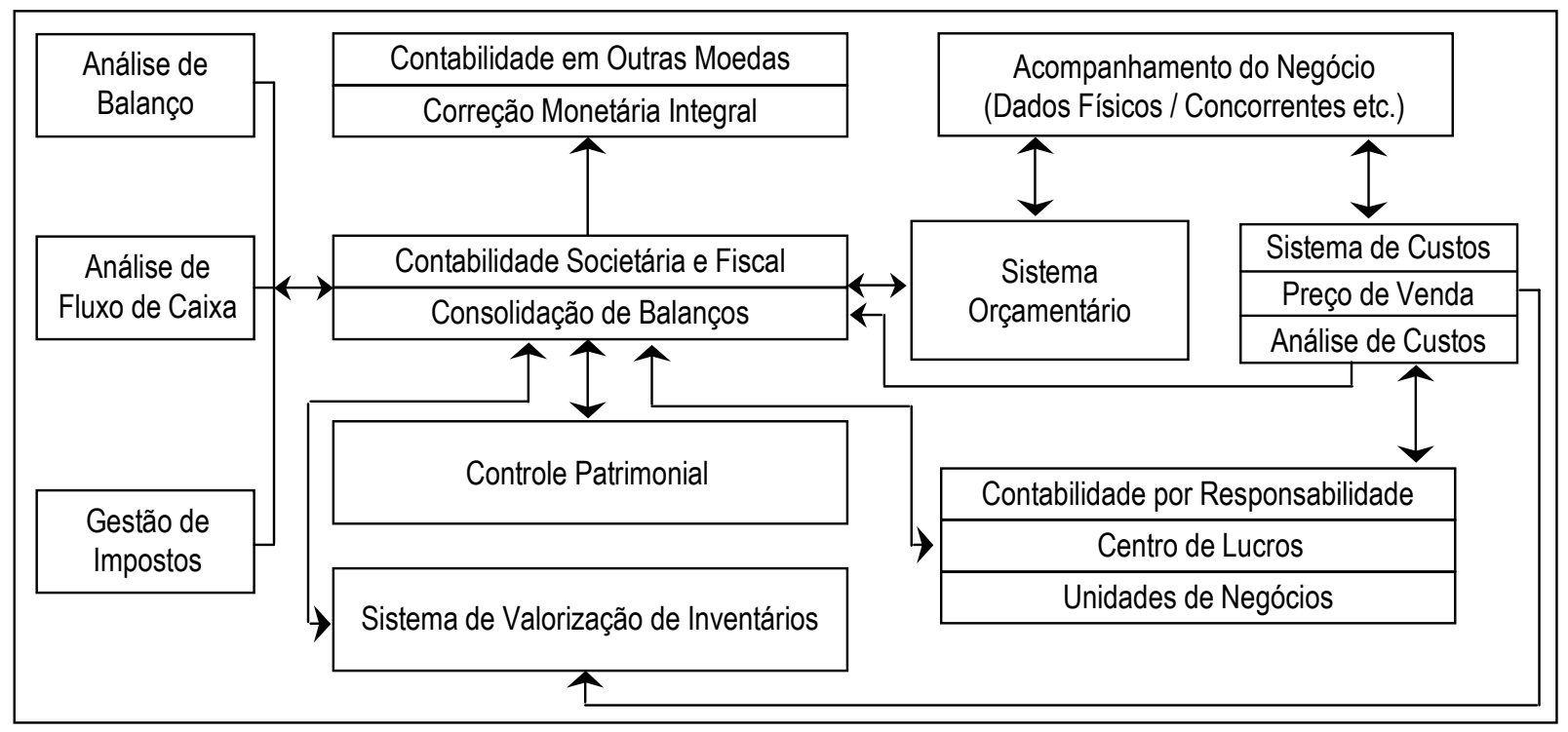

Figura 1 - Sistema de Informação Contábil

Fonte: PADOVEZE (2004, p.309)

\section{2 - Contabilidade de Custos}

A contabilidade de custos surgiu com o aparecimento das empresas industriais (Revolução Industrial) que tinha o intuito de determinar os custos dos produtos fabricados. Com a evolução e o crescimento das empresas e o conseqüente aumento na complexidade do sistema produtivo, constatou-se que as informações fornecidas pela contabilidade de custos são potencialmente úteis ao auxílio gerencial, extrapolando a mera determinação contábil do resultado do período.

A maior parte dos temas da disciplina contabilidade gerencial é tomada por outras disciplinas e sistemas das áreas de ciências contábeis ou administração financeira. 
De acordo com Lawrence (1997, p.26), a contabilidade de custos pode ser entendida como:

\begin{abstract}
"A Contabilidade de Custos (gestão de custos) é o processo ordenado de usar os princípios da contabilidade geral para registrar os custos de operação de um negócio, de tal maneira que, com os dados da produção e das vendas, se torne possível à administração utilizar as contas para estabelecer os custos de produção e de distribuição, tanto por unidade como pelo total, para um ou para todos os produtos fabricados ou serviços prestados e os custos das outras diversas funções do negócio, com a finalidade de obter operação eficiente, econômica e lucrativa" (LAWRENCE, 1997, p.26).
\end{abstract}

Horngren, et al. (1997, p.2) afirma que a contabilidade de custos é ciência que mensura e relata informações financeiras e não financeiras relacionadas a aquisição e ao consumo de recursos pela organização. Ela fornece informações tanto para a contabilidade gerencial quanto para a contabilidade financeira.

\title{
3.3 - Gestão Estratégica de Custos
}

A função da gestão estratégica de custos é apoiar a competitividade da empresa, fundando suas perspectivas de análise e de atuação, em um horizonte de longo prazo e em um reconhecimento não só puramente da gestão dos custos atuais como também na gestão dos recursos que propiciarão os ganhos futuros, ganhos estes baseados nas vantagens competitivas sustentáveis de mínimos custos e diferenciação no serviço.

Neste sentido, o conceito de estratégia está intimamente relacionado com a idéia de concorrência, sendo este último, encarado como um processo essencialmente dinâmico de criação, destruição e modificação de espaços econômicos no desenrolar da luta competitiva.

A administração dos custos dentro do campo estratégico é definida por Tachibana, Escrivão e Almada (1995, p.48), como "a inter-relação entre a gestão estratégica empresarial e a gestão organizacional objetivando integrar a produção na estratégia dos negócios".

O modelo econômico tradicional descrito por Ferguson (1986, p. 196) foca a maximização do lucro no curto prazo, porém o objetivo a ser defendido por empresas estratégicas é a busca da maximização da taxa de retorno no longo prazo baseado na 
geração de condições presentes favoráveis de seus setores de atuação (processos produtivos). Além dos objetivos de longo prazo, a empresa deve se preocupar com a manutenção do grau de flexibilidade capaz de ter capacidade de resposta a alterações imprevistas de mercado. Diante deste enfoque, o objetivo econômico da empresa surge então da conciliação destes três objetivos: a maximização do retorno, aprimoramento dos processos produtivos sustentadores da competitividade no longo prazo e o monitoramento do grau de flexibilidade.

Segundo Coutinho e Ferraz (1994, p.19), a competitividade de uma empresa, sobre um ponto de vista sistêmico, é resultante da articulação de três grupos de fatores (conforme figura 2): os internos à empresa, aqueles relacionados com o setor de atuação (estruturais) e os sistêmicos, que são específicos aos contextos nacionais e exógenos ao campo de atuação da empresa.

\begin{tabular}{|c|c|c|}
\hline $\begin{array}{l}\text { Fatores Estruturais } \\
\text { do Setor }\end{array}$ & $\begin{array}{l}\text { Fatores Internos à } \\
\text { Empresa }\end{array}$ & Fatores Sistêmicos \\
\hline Concorrentes & \multirow{2}{*}{$\begin{array}{c}\text { Capacidade empreendedora } \\
\text { dos Diretivos }\end{array}$} & Macroeconômicos \\
\hline Mercado & & Sociais \\
\hline \multirow{2}{*}{$\begin{array}{l}\text { Configurações da } \\
\text { Indústria }\end{array}$} & Estratégia & \multirow{2}{*}{$\begin{array}{l}\text { Fatores Político- } \\
\text { Institucionais } \\
\end{array}$} \\
\hline & Gestão & \\
\hline $\begin{array}{l}\text { Impactos de Produtos } \\
\text { Substitutos }\end{array}$ & Recursos Humanos & $\begin{array}{l}\text { Fatores Político- } \\
\text { Regulatórios }\end{array}$ \\
\hline $\begin{array}{l}\text { Fornecedores } \\
\end{array}$ & $\begin{array}{c}\text { Cultura } \\
\end{array}$ & Ambientais \\
\hline Tecnologia & Capacidade Operacional & Tecnológicos \\
\hline \multirow{2}{*}{$\begin{array}{c}\text { Ameaça dos } \\
\text { Entrantes }\end{array}$} & Mobilidade do Capital & \multirow{2}{*}{$\begin{array}{l}\text { Mercadológicos } \\
\text { Internacionais }\end{array}$} \\
\hline & Capacidade de Inovação & \\
\hline 4 & & 4 \\
\hline
\end{tabular}

Figura 2 - Fatores Determinantes da Competitividade da Empresa Fonte: Coutinho e Ferraz (1994, p.19)

Dentro da gestão estratégica de custos, a sistemática de custeio ABC (Activity Based Cost - Custo Baseado em Atividades) é colocada como facilitador de mudanças na empresa, dado que o processo é aperfeiçoável, no sentido de que a ênfase está no método mais exato de cálculo, no aperfeiçoamento dos processos e na busca de um 
nível superior de qualidade na gestão empresarial, transferindo a preocupação para a melhoria da posição competitiva via gestão de custos.

Bacic (1994, p.7) apresenta outro enfoque a gestão estratégica de custos quando afirma que a empresa deve se preocupar com a manutenção de recursos suficientes para antecipar e liderar mudanças mercadológicas. Nesse sentido, a Gestão Estratégica não deve ser entendida como gestão de "sacrifícios a serem minimizados" e sim como gestão estratégica de recursos de forma a criar e propiciar ganhos em um horizonte de longo prazo atacando os seguintes pontos:

- aprender a avaliar, no presente, os custos futuros de tendências estratégicas que destroem fatores internos de competitividade;

- aperfeiçoar metodologias de avaliação de custos no longo prazo;

- relacionamento consistente entre a Gestão Estratégica de Custos com a estratégia global da empresa;

- aprender a criar novas realidades (simulação), em termos de utilização de recursos atuais e potenciais que possibilitem maiores ganhos;

- buscar a identificação de custos ocultos da complexidade empresarial e propor políticas para sua redução.

\section{4 - Metodologias de Custeio}

Metodologia, referenciada pelo estudo de gerenciamento de custos, pode ser entendida com um conjunto de regras sistematizadas de planejamento da coleta de dados, objetivando a análise de resultados e a elaboração de decisões. $E$ para isso são apresentadas três estruturas de custeio que se apresentam eficazes no alcance deste objetivo.

\subsection{1 - Metodologia dos Centros de Custo}

Centro de Custo é a unidade da empresa destinada à acumulação de informações contábeis referentes a transações produtivas, alocação de custos e investimentos. 
Centro de custos (centro de despesas, de gastos) são unidades contábeis de acumulação utilizadas para alocar os gastos por setor e por atividade. Os centros de custos acumulam, em um primeiro momento, apenas os gastos da atividade, não havendo preocupação com possíveis receitas de cada um desses centros de responsabilidades. (PADOVEZE, 2004, 263-264)

Os centros de responsabilidades tratados pelo autor são: centro de custos, de lucros e de investimentos.

Bornia (2009, p.89) afirma, quanto à determinação dos centros de custos, que:

\begin{abstract}
"os centros são determinados considerando-se o organograma (cada setor da empresa pode ser um centro de custos), a localização (quando partes da empresa encontram-se em localidades diferentes, cada local pode ser um centro), as responsabilidades (cada gerente pode ter sob sua responsabilidade um centro de custos) e a homogeneidade".
\end{abstract}

Dentro da ótica das responsabilidades empresariais, os centros de custos podem também representar cada processo produtivo da empresa (cada gerente pode ter sob sua responsabilidade um centro de custo). O procedimento de implantação do método dos centros de custos pode ser sintetizado em cinco etapas:

- separação dos custos (recursos) em itens ou componentes;

- identificação dos processos produtivos e sua respectiva segregação em centros de custos;

- identificação dos custos com os centros (distribuição primária);

- alocação dos custos dos centros de custos indiretos até os diretos (distribuição secundária) e

- alocação dos custos dos centros diretos aos serviços.

A primeira etapa consiste na segregação dos custos em componentes básicos da organização. Em empresas de Tecnologia da Informação e Comunicação - TIC, por exemplo, podemos citar alguns exemplos típicos de custos: Pessoal, Hardware, Software, Circuito (Comunicação), etc. Esses custos podem também ser definidos como recursos disponíveis para produção. Esta etapa é trivial a qualquer metodologia de custos, pois trata apenas de uma organização dos recursos. 
A segunda etapa consiste na identificação dos processos produtivos da empresa e a respectiva representação de cada processo por um centro de custo, considerando, conforme Bornia (2009, p.89) a localidade de produção como uma "sub-divisão" do centro de custos.

Os centros de custos são os verdadeiros consumidores dos recursos, refletindo o propósito da terceira etapa, que consiste simplesmente na alocação dos custos dos recursos aos respectivos centros (distribuição primária). A distribuição dos custos deve representar da melhor forma possível o uso dos recursos. Como os custos são os valores dos insumos utilizados, a distribuição dos custos deve respeitar o consumo desses insumos pelos centros.

A quarta etapa envolve os centros de custos indiretos, que, conforme o autor, têm o objetivo de prestar apoio aos demais centros, não trabalhando diretamente para o produto ou serviço. Esta distribuição secundária deve respeitar o consumo (sequencial) desse centro pelos demais. Bornia (2009, p.90) denomina de Alocação de Múltiplos Estágios as distribuições primária e secundária, "pois a alocação é efetuada em várias fases".

A última etapa (distribuição final) consiste na distribuição dos custos dos centros de custos diretos aos serviços, já suportados os centros indiretos. Para isso, o critério a ser empregado é uma unidade de medida do trabalho do centro de custo direto, que deve representar o esforço dedicado a cada serviço.

Segue, abaixo, uma esquematização gráfica, denominada na literatura da contabilidade de custos como Matriz de Custos.

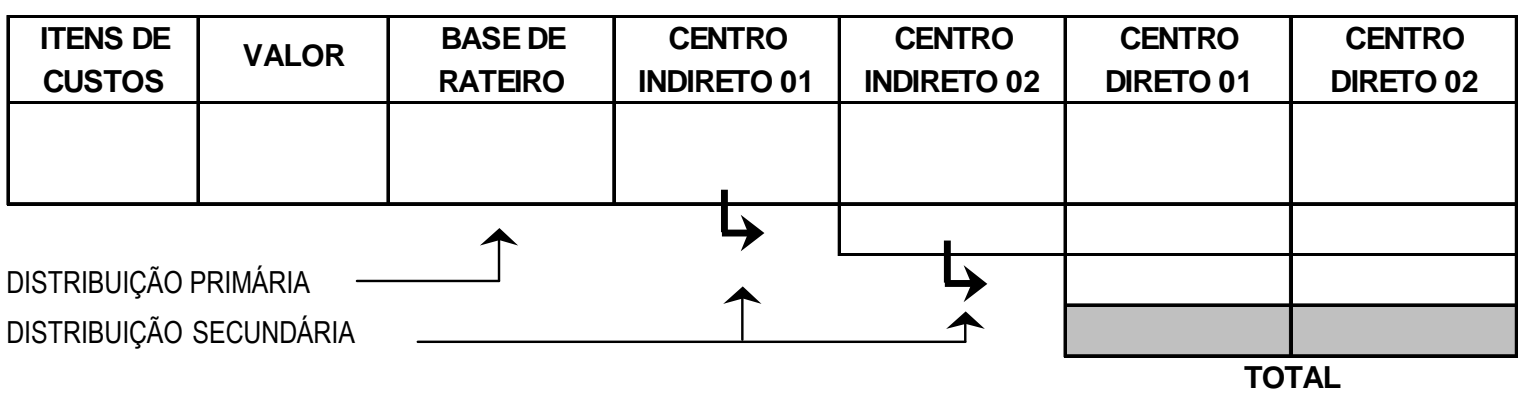

Figura 3 - Matriz de Custos

Fonte: Bornia (2009, p.94) 
O autor apresenta um ponto que pode ser considerado desfavorável à metodologia de centros de custos quando menciona: "podemos dizer que, quando o centro é direto, é possível conseguir-se uma boa alocação dos custos dos centros aos produtos. Entretanto, quando o centro é indireto, isso não ocorre, sendo mais fácil e lógico relacionar seus custos com outros centros do que diretamente com os produtos. Por isso, os procedimentos do método dos centros de custos são um pouco mais complexos".

\subsection{2 - Metodologia de Custeio Baseado em Atividades (ABC)}

É sabido, e conforme demonstrado no início deste referencial teórico, que o setor de serviços vem crescendo ano após ano, passando a ocupar cada vez mais espaço no moderno ambiente de negócios. Com a evolução econômica e o aumento da competitividade, o setor passou a buscar novos conceitos em gerenciamento para que pudesse acompanhar esses mercados cada vez mais exigentes. Apesar das características diferentes em relação ao setor de manufatura, o setor de serviços vem buscando e adaptando conceitos utilizados com sucesso nessa área.

A busca de um sistema de custeio que atendesse aos seus anseios fez com que as empresas de serviços descobrissem, na manufatura, o Activity Based Cost (Custo Baseado em Atividades). Este se mostrou extremamente eficiente e trouxe informações de grande valia para o gerenciamento eficaz dessas organizações.

O Sistema de Custeio Baseado em Atividades é a metodologia que atribui os custos de apoio aos produtos ou serviços na proporção da demanda que cada serviço exerce sobre várias atividades. O sistema desenvolve a idéia de direcionadores de custos que vincula, diretamente, as atividades executadas aos produtos/serviços desenvolvidos. Esses direcionadores de custos medem o consumo médio ocorrido, em cada atividade, pelos vários serviços.

A vantagem de se ter um sistema de custeio baseado em atividades é a possibilidade de associar os custos dos recursos aos respectivos clientes e às receitas geradas. Somente pela compreensão dessa associação e da ligação entre preços, 
recursos, uso e melhoria de processos, os gerentes podem tomar decisões eficazes quanto às decisões de viabilidade de manter ou não um processo ativo.

Fama e Habid (1999), reconhecem que o sistema de custeio ABC, para custos não fabris, permite: melhorar o entendimento para gerenciar as linhas de serviços, melhorar processos de organização, analisar possibilidade de otimização de custos nas atividades de valor elevado, enfocar melhoria contínua dos custos de processos e utilizar as abordagens de custos por atividade e por processos para efeito de "benchmarking" com outras empresas similares.

Perez e Oliveira (2000, p.165) afirmam que: "O custeio baseado em atividades é uma metodologia que surgiu como instrumento da análise estratégica de custos relacionados com as atividades que mais impactam o consumo de recursos de uma empresa".

Nakagawa (1994, p.29) considera o ABC como "um novo método de análise de custos, que busca "rastrear" os gastos de uma empresa para analisar e monitorar as diversas rotas de consumo dos recursos diretamente identificáveis com suas atividades mais relevantes, e destas para os produtos e serviços".

Segundo Berts e Kock (1995, p.57), uma organização de serviços que implanta o $A B C$ deve estar voltada para o mercado e focada na qualidade para saber se os serviços produzidos são considerados como valor agregado pelo cliente. Num mercado competitivo, melhorias contínuas de qualidade e redução de custos têm que acontecer. A empresa deve manter estudos de como ela está trabalhando para não cometer equívocos que conduzam a um serviço ineficiente. Estudos sobre a qualidade percebida também devem ser feitos para saber quais os serviços que são desejados e considerados de valor agregado pelos clientes. Se a qualidade percebida de um cliente está em linha com suas expectativas, ou as excede, assume-se que ele está satisfeito. Ainda segundo o autor, as empresas de serviços ao implantarem o ABC devem estar cientes de que:

- clientes exigem serviços que, frequentemente, aumentam as despesas empresariais sem um aumento correspondente na receita. Portanto, é fundamental que se entendam os custos das atividades envolvidas no serviço para melhor gerenciá-los; 
- hierarquizar as atividades em níveis de unidade, lotes, sustentação de produtos e sustentação de instalações favorece uma análise mais apropriada do consumo dos recursos pelas atividades e de como estas são utilizadas pelos serviços.

- em empresas cujo trabalhador desempenha suas tarefas em atividades múltiplas, fica difícil de se controlar o tempo dedicado para uma atividade específica;

Pode-se notar que a metodologia $A B C$ surge como o método de custeio mais diversificado na literatura, onde a variação se dá pelos princípios de implantação do sistema, ou seja, o âmbito estratégico (quais informações serão obtidas e para que serão utilizadas) ligado à melhoria de processos e redução de desperdícios o que leva o sistema $A B C$ a ser a forma mais refinada de mensuração e alocação dos custos, não exigindo nenhum ajuste em termos de teoria contábil, a diferença está na complexidade e variabilidade dos processos produtivos.

Para Kaplan e Cooper (1998, p.122), "Os sistemas de custeio baseado na atividade oferecem informações de custos mais precisas sobre atividades e processos de negócios e sobre produtos, serviços e clientes servidos por esses processos. Os sistemas $A B C$ focalizam as atividades organizacionais como elemento-chave para análise do comportamento do custo, associando as despesas organizacionais destinadas aos recursos".

Os procedimentos do $\mathrm{ABC}$ consistem primeiramente em seccionar a empresa em atividades, e posteriormente, calcular o custo de cada atividade, compreender o comportamento dessas atividades, identificar as causas dos custos relacionados, e em seguida, alocar os custos aos serviços de acordo com as intensidades de uso, conforme esquematizado abaixo. 


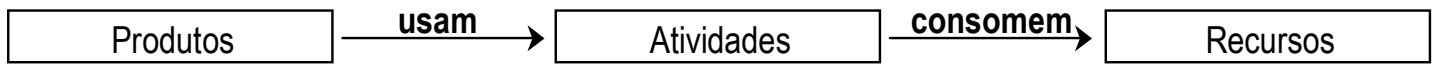

(a) Lógica de funcionamento.

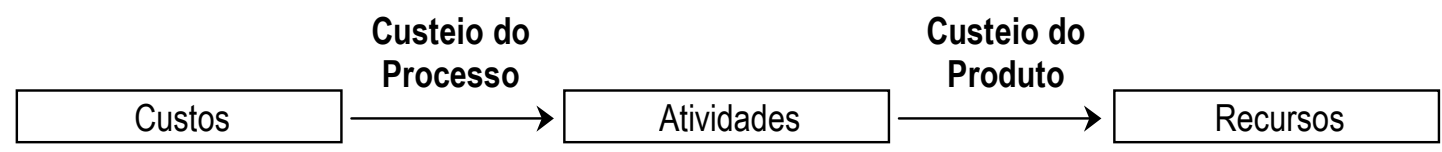

(b) Modelo

Figura 4 - ABC

Fonte: Bornia (2009, p.112)

Segundo Penha e Lira (1999, p.8): "A essência do método ABC é apurar os custos com base nas mais diversas atividades desenvolvidas pela empresa segundo 0 triedo: Recursos; Atividades e Objetos de Custos. O método considera, em primeiro lugar, que as diversas atividades desenvolvidas pela empresa são as legítimas demandantes dos mais variados recursos utilizados. Por último, os objeto de custos produtos, serviços, clientes, e contratos - são quem consomem as atividades na condição terminal de apuração de custos.

O método de centros de custos pode ser considerado como uma premissa para a implantação do sistema ABC. Para Bornia (2009, p.114), na ótica do método, o ABC pode ser entendido como uma evolução do método de Centros de Custos, onde são consideradas quatro fases para o cálculo dos custos.

- mapeamento das atividades;

- distribuição dos custos às atividades;

- distribuição dos custos das atividades indiretas até as diretas;

- distribuição dos custos diretos aos serviços.

$\mathrm{Na}$ primeira etapa do $\mathrm{ABC}$ temos um dos pontos cruciais para uma boa implementação do sistema. A organização deve ser modelada em atividades, as quais, encadeadas, formam os processos, conforme ilustrado na Figura 5. Os níveis de detalhamento vão determinar a qualidade do modelo e, consequentemente, a adequabilidade das informações para os objetivos pretendidos. Quanto mais detalhadas forem as atividades, mais facilmente o gerente pode detectar possíveis melhorias, 
porém a implantação e a manutenção ficam mais onerosas. Portanto, se o objetivo for meramente o cálculo dos custos dos serviços, pode-se usar um menor grau de detalhamento, ao passo que, se o objetivo for apoio ao controle operacional e a melhoria dos processos, é necessário detalhar ao nível de atividades.

Nakagawa (1994,p.42) define atividade como sendo "um processo que combina, de forma adequada, pessoas, tecnologias, materiais, métodos e ambientes, tendo como objetivo a produção de produtos. Em sentido mais amplo, entretanto, atividade não se refere apenas a processo de manufatura, mas também a produção de projetos, serviços, etc., bem com as inúmeras ações de suporte a esses processos."

A segunda etapa consiste na alocação dos custos dos recursos disponíveis para produção às respectivas atividades consumidoras, conforme figura 4 (Lógica de Funcionamento). As atividades são os verdadeiros consumidores de recursos e este consumo é o que denominamos de distribuição primária

A terceira etapa, ainda segundo Bornia (2009, p.114), é a fase de identificação das atividades indiretas (atividades de apoio), e suas respectivas estruturas de custos. Esta etapa, também conhecida como distribuição secundária, consiste, inclusive, no direcionamento (direcionadores de custos) destes custos às atividades diretas respeitando a proporcionalidade dos respectivos consumos.

A última etapa consiste na alocação dos custos aos serviços, que segundo Penha e Lira (1999, p.122) é a condição terminal de apuração de custos.

Para um melhor entendimento, segue abaixo o detalhamento, ao nível de atividade, de um processo de apuração de custos descrito por Bornia (2009, p.115). 


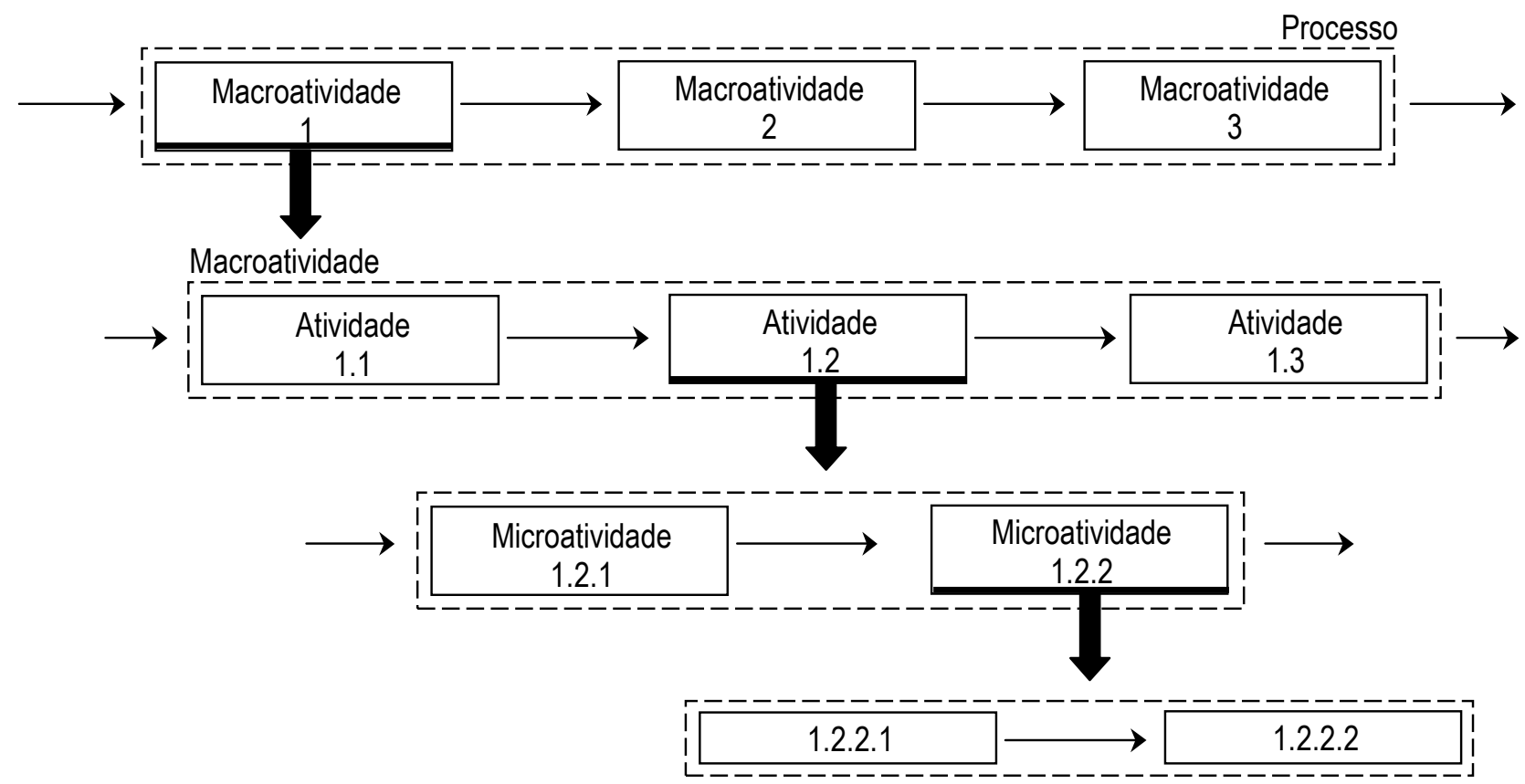

Figura 5 - Detalhamento de um processo

Fonte: Bornia (2009, p.115)

As informações fornecidas pelo $A B C$ servem para dirigir a atenção da gerência às atividades responsáveis pelos custos, possibilitando melhor visualização dos impactos causados por decisões e melhor controle dos custos fixos. Esse é um modelo de apoio a decisões de longo prazo, pois considera que a atuação sobres as atividades provocará modificações nos custos fixos.

\subsection{3 - Total Cost of Ownership (TCO)}

Devido ao crescimento do volume de recursos destinados às empresas prestadoras de serviços de Tecnologia da Informação e Comunicação (TIC), houve uma necessidade de um maior controle de gastos, não só dos investimentos propriamente dito em TIC, mas também uma compreensão detalhada do seu impacto. Com isso, surgiu, em 1987, o Total Cost of Ownership ou o Custo Total de Propriedade, uma metodologia de custeio criada por Group Gartner para atendimento exclusivo de empresa fornecedoras (desenvolvedoras) de solução de TIC. Segundo Canto (1996) o termo TCO se refere ao custo da infra-estrutura de tecnologia alocado por uma 
organização para todo o ciclo de vida de um projeto específico, considerado aqui aquisição de hardware e software, alocação de usuário, desenvolvimento, suporte, gerenciamento, comunicação - rede, realocação, disposição e venda. Segundo o mesmo autor, as vantagens de se implantar esta metodologia de avaliação dos custos de informática são as seguintes:

- A necessidade de identificação pontual dos recursos humanos disponíveis na empresa com suas respectivas especializações;

- Avaliar a viabilidade de desenvolvimento de sistemas internamente ou externamente;

- Definir inicialmente as soluções que provavelmente gerarão maiores impactos;

- Ser criterioso na seleção de fornecedores externos para a área de informática.

Portanto, a metodologia permite aplicar, nas empresas prestadoras de serviços de Tecnologia da Informação e Comunicação, conceitos e controles aplicados à contabilidade gerencial e na administração financeira como: análise de viabilidade de projeto e retorno do investimento.

Segundo Gasparetto (1999) a metodologia Total Cost of Ownership pode ser entendida da seguinte maneira:

O TCO reconhece que os custos de aquisição de um item não são somente aqueles do item propriamente dito, mas de todas as atividades executadas para que o item seja adquirido e utilizado. Assim, as atividades envolvidas no recebimento dos suprimentos podem ser associadas aos vários fornecedores da empresa, com o objetivo de identificar gastos gerados por cada um deles e, a partir daí, esses gastos podem ser utilizados para a avaliação desses fornecedores (GASPARETTO, 1999).

\section{5 - Custo para Controle e Custos Padrões}

Quando surge algum problema no processo (sistema produtivo), haverá aumento nos custos totais e/ou redução na produção. Em ambos os casos, o custo unitário do 
produto vai aumentar, indicando a ocorrência do problema ao gerente. Portanto, uma importante finalidade de sistemas de custos é o auxílio ao controle. Controlar um determinado processo consiste em se determinar um padrão ou expectativa de desempenho para esse processo, verificar seu desempenho real, procurar as causas das variações ocorridas e, finalmente, tomar ações corretivas para corrigir eventuais problemas observados. Em se falando de sistemas de custos determina-se o comportamento desejado ou esperado para os custos e procede-se à avaliação dos custos incorridos no período. A comparação dos resultados obtidos, então, é possível, abrindo caminho para a análise dos motivos das variações encontradas e para a busca de soluções visando a melhoria do processo.

Padrão pode se entendido como uma base ou norma que serve para a avaliação de qualidade, quantidade ou de medida. Para Garrison e Noreen (2001, p. 306) um padrão é uma referencia (benchmarking), ou uma "norma", para a avaliação de desempenho.

O objetivo de se estabelecer as expectativas de custos padrões é comparar, em momentos posteriores de apuração, estas previsões com os custos e as quantidades reais de produção. Se a quantidade e/ou o custo de produção dos recursos se afastam significantemente dos padrões estabelecidos, os gerentes devem investigar as discrepâncias com o intuito de descobrir possíveis causas do problema, e se houver eliminá-las. Para Garrison e Noreen (2001, p.306) este processo é denominado de “Administração por exceção".

A idéia básica do uso de custos para controle é fornecer um padrão de comportamento para os custos, ou seja, fixar quais deveriam ser os montantes para, ao final da apuração dos custos do período, proceder-se à comparação com os custos realmente ocorridos. As diferenças existentes entre o padrão e o real são, então, evidenciadas e analisadas. Assim, o procedimento do custo padrão consiste em:

- fixar um custo padrão, o qual servirá de referência para a análise dos custos;

- determinar o custo realmente incorrido;

- levantar as variações (desvios) ocorridas entre o padrão e o real; e

- analisar a variação, a fim de auxiliar a procura pelas causas (motivos) que levaram aos desvios. 
Garrison e Noreen (2001, p. 310) apresentam em seu livro um modelo geral de análise (entendimento) de variações de preços e quantidades (conforme figura abaixo), podendo ser facilmente adaptável a uma modelagem de custos:

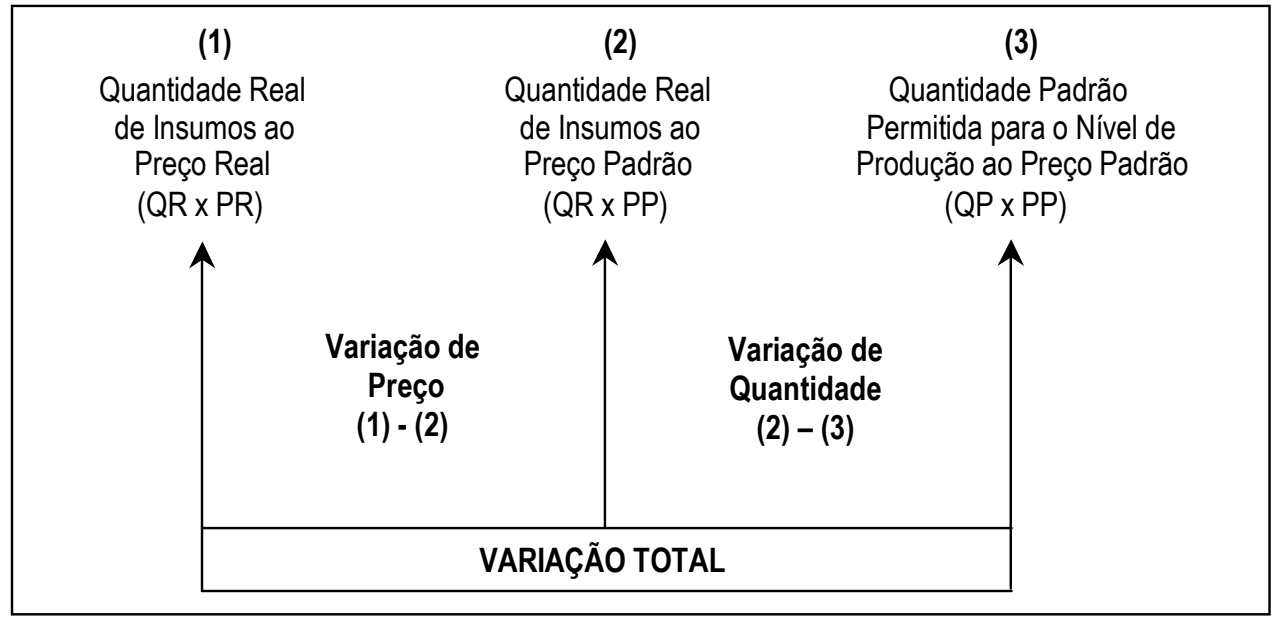

Figura 6 - Modelo Geral de Análise de Variações - Custos Variáveis

Fonte: Garrison e Noreen (2001, p. 310)

Em regra, os padrões são estabelecidos para que sejam alcançados, porém a forma com que as empresas irão buscar o resultado depende do grau de exigência dos padrões estabelecidos. Para Garrison e Noreen (2001) estabelecem dois níveis de estabelecimento de padrões, a saber:

- Padrão Ideal: são aqueles que só podem ser alcançados dentro das melhores circunstâncias. Não admitem falhas do equipamento ou outras interrupções no trabalho e exigem nível de empenho que somente pode ser atingidos pelos empregados mais qualificados e eficientes, trabalhando com empenho máximo todo o tempo.

- Padrão prático: são definidos como aqueles que são "apertados, mas passíveis de serem alcançados". Eles admitem tempo de paralisação normal das máquinas e períodos de descanso dos empregados, e podem ser alcançados mediante um empenho razoável, embora altamente eficiente, considerando-se o trabalhador médio. 
A fixação do padrão pode ser feita com maior ou menor rigidez, dependendo dos objetivos a que se propõe. Um padrão mais apertado, só atingido em condições ideais de fabricação, se presta a uma meta de longo prazo, podendo apresentar problemas de motivação a curto prazo. Esse padrão ideal não é muito empregado para efeitos de avaliação de desempenho. O ideal é adotar um padrão mais realista que considere as deficiências empresariais. Cabe ressaltar que: quanto mais requintado for 0 estabelecimento dos padrões de custos, mais difícil e oneroso se torna à implantação de um modelo que alcance os resultados.

\section{6 - Ociosidades ou Desperdícios}

Empresas modernas prestadoras de serviços precisam necessariamente concentrar esforços na busca constante de melhoria em seus processos produtivos, e uma das maneiras de propiciar essa evolução é focar na eliminação de desperdícios.

Dentro da visão da contabilidade de custos, entende-se por desperdício, todo o insumo consumido de forma não eficiente, desde materiais e serviços defeituosos até atividades desnecessárias, que em empresas prestadoras de serviços, são perdas, não consideradas no enfoque contábil do estoque. Bornia $(2009$, p.6) trata o desperdício da seguinte maneira:

\footnotetext{
"Os esforços da empresa podem ser divididos em trabalho e desperdício. 0 trabalho pode ser subdividido em trabalho que agrega valor e trabalho que não agrega valor. $\mathrm{O}$ trabalho que agrega valor, ou trabalho efetivo, compreende as atividades que realmente aumentam o valor do produto, sob a ótica do consumidor. O trabalho que não agrega valor, ou trabalho adicional, compreende as atividades que não aumentam o valor do produto, mas propiciam suporte para o trabalho efetivo. O desperdício propriamente dito não adicionam valor aos produtos e também não são necessários ao trabalho efetivo. Nesta categoria, situam-se a produção de itens defeituosos, a movimentação desnecessária, a inspeção de qualidade e a capacidade ociosa."
}

O mesmo autor também faz uma segregação, dentro do conceito de desperdício, em normal e anormal, onde explica que o objetivo da separação é o fato de como as perdas serão atacadas pela empresa. Os desperdícios anormais são aqueles que poderão ser eliminados no curto prazo (perdas que não deveriam ter ocorrido 
considerando-se o sistema produtivo atual), ao passo que os normais podem ser atacados no longo prazo, dentro de um conceito de melhoria do sistema produtivo.

Garrison e Noreen (2001) apresentam a seguinte visão da ociosidade direcionada ao custo de mão-de-obra:

\begin{abstract}
O tempo ocioso representa o custo da mão-de-obra dos trabalhadores que não podem executar suas atribuições, devido a avarias na maquinaria, falta de material, interrupção da energia e coisas do gênero. Embora operários de mãode-obra direta estejam envolvidos, os custos referentes tempo ocioso são considerados parte do custo indireto de fabricação, em vez da parte do custo da mão-de-obra direta, porque os gerentes acham que tais custos devem ser distribuídos por toda a produção do período e não apenas pelos produtos que estavam em execução.
\end{abstract}

Conforme as classificações dos desperdícios de Shingo (1981), além dos desperdícios por fabricação de serviços defeituosos, há um desperdício típico de empresas prestadoras de serviços, os desperdícios por espera (capacidade ociosa), que consiste em se ter trabalhadores e instalações paradas, o que gera custos. Empresarialmente, esses custos oscilam de acordo com o grau de vinculação dos seguintes fatores: falta de sincronismo entre a produção, falhas não previstas no sistema produtivo e aquisições de recursos acima do necessário ou antecipadamente (falta de uma política de investimento empresarial e falta de controle de capacidade de produção).

De forma geral, o foco no combate aos desperdícios é uma ferramenta poderosa para a racionalização do processo produtivo e, conseqüentemente, para a redução dos custos. Neste sentido, um dos principais objetivos de uma sistemática de gerenciamento de custos é a detecção dos desperdícios ocorridos durante suas atividades, pois a grande concorrência atual exige especialização e competência nas atividades da empresa. A identificação e quantificação dos desperdícios de uma empresa é, sem dúvida, útil para auxiliar o processo de análise e melhoria da eficiência interna dos processos produtivos. 


\section{DESENVOLVIMENTO}

\section{1 - Diretrizes para implantação de um Sistema de Custeio ABC em Empresas Públicas prestadoras de serviços}

Segundo Ferreira (1975, p.479) diretriz é definido como: "Conjunto de instruções ou indicações para se tratar e levar a termo um plano, uma ação, um negócio, etc.".

Antes de descrever as etapas do processo de implantação de um sistema de custos é importante mencionar que é necessário conhecer a estrutura administrativa, produtiva e gerencial da empresa, para que sejam definidos os objetivos a serem atingidos pelo sistema a ser implantado, esses objetivos serão formulados de acordo com o nível de controle existente e a necessidade de informação para a tomada de decisões. Logicamente que, para o desenvolvimento de um sistema de custo para empresas prestadoras de serviços públicos, o demandante deve, necessariamente, conhecer os serviços prestados e os sistemas de produção, e para isso, sugere-se que sejam realizadas visitas técnicas as fábricas, entrevistas com o pessoal de produção e o levantamento detalhado de cada atividade inerente ao processo de produção em busca do melhor entendimento empresarial. A garantia de sucesso na implantação do sistema de custeio do tipo $A B C$ requer estes desafios inevitáveis.

Primeiramente é necessário apresentar conceitos e considerações para o entendimento geral:

Segundo Kotler (1994, p.403), a definição de serviço é: "qualquer ato ou desempenho que uma parte pode oferecer a outra e que seja essencialmente intangível e não resulta na propriedade de nada. Sua produção pode ou não estar vinculada a um produto físico".

A análise de um sistema de custos pode ser efetuada sob dois pontos de vista, que segundo Bornia (2009, p.30), podem ser denominados de princípio e método, que consiste em analisar, sob o enfoque do princípio, se o tipo de informação gerada é adequado às necessidades da empresa e quais seriam as informações importantes que deveriam ser fornecidas. Essa discussão está relacionada com os objetivos do sistema, pois a relevância das informações depende de sua finalidade. Assim, o que é 
importante para uma decisão pode não ser válida para outra. Sob o enfoque do método, o objeto do estudo do sistema diz respeito à parte operacional do mesmo, ou seja, como os dados são processados para a obtenção das informações.

Para ser bem sucedida na implantação de um sistema de custos, a empresa deve implantar em seu ambiente operacional uma tecnologia de gestão compatível com as suas necessidades gerenciais de controle dos elementos que compõem seus serviços, proporcionando a identificação de ocorrências de problemas ou situações não previstas através de comparação com padrões e orçamentos, de avaliação dos resultados, de análise de margens de contribuição, de tomada de decisões de mudanças em processos de produção, de análise dos benefícios da utilização de tecnologias avançadas de produção e de apoio ao planejamento estratégico da organização.

A implantação de um sistema de custeio baseado em atividades em empresas prestadoras de serviços requer, primeiramente, o conhecimento, através de mapeamento dos processos empresariais, das seguintes etapas:

- Primeira Etapa: a identificação dos recursos disponíveis para produção dos serviços, bem como, a organização dos mesmos de acordo com as suas homogeneidades, ou seja, conforme definição de Kaplan e Cooper (1998, p.101) estes recursos podem ser entendidos como o "agrupamento isolado e homogêneo de custos existentes que representam uma função semelhante ou, no caso de pessoas, que têm um perfil de trabalho semelhante. A soma de todos os recursos incluídos em um modelo equivale ao custo total de uma organização, dentro de um período de tempo determinado".

Bornia (2009, p. 89) afirma que "um centro é homogêneo se o trabalho realizado nele independe do produto que o utiliza, ou seja, todos os produtos que passam pelo centro sofrem o mesmo tipo de trabalho".

- Segunda Etapa: a identificação de todas as atividades inerentes aos processos produtivos da empresa ao qual se pretende implantar o sistema de custeio. É vinculado a esta etapa, por analogia, o conceito de distribuição primária, que é o consumo dos recursos disponíveis pelas atividades. Simultaneamente a estas identificações se faz 
necessário a classificação dos respectivos custos inerentes a cada atividade em diretos e indiretos, pois, o objetivo também é prover o gerenciamento e rateios alinhados à estrutura de custeio ABC.

- Terceira Etapa: a identificação, em termos de custos, dos critérios de agrupamento das atividades aos objetos de custos (componente do serviço final). Por analogia ao referencial teórico, esta etapa consiste na distribuição secundária, ou seja, o consumo das atividades pelos objetos de custos;

- Quarta Etapa: é a alocação dos custos dos objetos de custos aos serviços prestados. É a fase final da alocação dos custos.

É importante, no momento da definição das regras da cadeia de valor, levar em consideração os aspectos gerenciais de planejamento vinculados a estrutura do sistema de custeio $A B C$ :

- Aspectos Operacionais: aspectos direcionados a análise da eficiência da produtividade;

- Aspectos Táticos: aspectos de gerenciamento funcional ao nível de unidade organizacional (aspecto setorial) voltado ao combate de falhas e controles internos.

- Aspectos Estratégicos: aspectos direcionados a rentabilidade dos serviços produzidos - aspectos inerentes a política de precificação e ao equilíbrio econômicofinanceiro empresarial.

Definida a cadeia específica de alocação dos custos em uma empresa pública de prestação de serviços, o próximo passo é, antes mesmo da efetiva apuração, estabelecer alguns padrões a serem alcançados (custo para controle / custo padrão). Nesta fase, o gestor do processo de implantação, deve estabelecer critérios de previsibilidade dos custos, que nada mais é que utilizar técnicas estatísticas de previsão com base em informações históricas (séries temporais) existentes na empresa. Esta técnica facilitará ao gestor a identificação desvios e falhas no decorrer do processo de apuração de custos, que podem ser desde dificuldades conceituais como dificuldades de implantação do próprio modelo. A idéia aqui é estabelecer um Roteiro de Custos (comportamento), mesmo que no momento do confronto entre o previsto e o real, possa 
notar que o mesmo não foi seguido. É aí que começa a necessidade do gestor de identificar os motivos (falhas e desvios) do não cumprimento do Roteiro de Custo anteriormente estabelecido.

O termo padrão é amplamente utilizado na contabilidade gerencial de custos e tem o sentido de relacionar os custos e as quantidades dos insumos empregados na produção de bem ou na prestação de um serviço, ou seja, os padrões indicam quanto de um determinado insumo ou recurso de ser usado para a realização de um serviço. Portanto, em linhas gerais, os custos padrões indicam qual deve ser a expectativa (previsão) dos custos reais.

O interessante nesta fase da previsibilidade é estabelecer roteiros de custos ao nível de atividade devido ao modelo a ser implantado ser o custeio baseado em atividades. A recomendação é que, se a empresa apresentar um alto grau de complexidade em suas atividades será necessário a descentralização da ação de previsibilidade da atividade, ou seja, envolver, neste momento o gestor de cada processo produtivo. Outro ponto de ganho com esta atitude é promover o comprometimento do corpo funcional neste assunto tão áspero que é custos.

Com a cadeia de alocação dos custos estabelecida e com os critérios e cálculos de previsibilidade definidos e efetuados, inicia-se propriamente a apuração real dos custos empresariais ao nível de atividade. Neste momento é verificar a aderência do modelo proposto de $\mathrm{ABC}$ com a estrutura organizacional disponível, com o nível de granularidade de medição dos processos produtivos, com a compreensão e com entendimento do corpo funcional e principalmente com a disseminação das vantagens e dos objetivos a serem atingidos. Se tudo aquilo que foi estabelecido anteriormente é realmente passível de medição, ótimo, se não, há a necessidade de identificar e combater os obstáculos.

Uma diretriz fundamental para o sucesso na implantação da sistemática de custeio $A B C$ é estabelecer previamente qual a estratégia empresarial a ser perseguida (vide figura abaixo): 


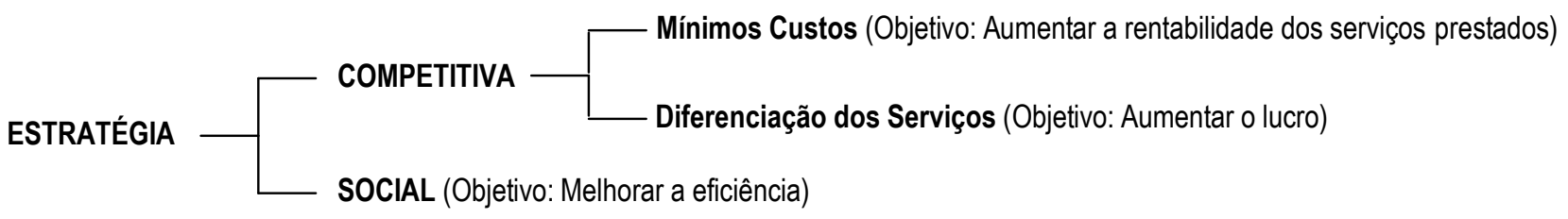

Figura 7: Estratégias

Independente da estratégia estabelecida, a vantagem de ser trabalhar com o Custeio Baseado em Atividades é que processo de gestão torna-se mais eficaz. $\mathrm{O}$ plano de gestão apresentado para esta metodologia é o Activity Based Management ABM (Gestão Baseada em Atividades), que é o processo administrativo que usa a informação fornecida por uma análise dos custos baseados em atividades para melhorar a rentabilidade da empresa. Este processo de gestão inclui a execução mais eficiente das atividades, eliminando a necessidade de executar certas atividades que não adicionam valor para os clientes, melhorando o projeto dos produtos e serviços com redução de recursos organizacionais, sendo base de ação para as seguintes decisões:

- Modificar preços, mix de produtos e mix de clientes;

- Melhorar o relacionamento com fornecedores e clientes;

- Aprimorar o desenho de produtos e serviços (reengenharia);

- Executar atividades com eficiência;

- Eliminar certas atividades que não criam valor para os clientes.

A Gestão proativa e preditiva de sistemas de custeio baseado em atividades permitem os gerentes tomarem melhores decisões, fazendo com que as previsões antecipem os eventos efetivos e influencie comportamentos futuros dos custos.

\subsection{1 - Considerações à implantação do modelo}

A primeira consideração a ser apresentada é o fato das empresas públicas prestadoras de serviços terem uma representatividade dos custos da mão-de-obra em 
relação aos custos estruturais totais em torno de $75 \%$, conforme verificado no Congresso de Gestão de Custos na Administração Pública, realizado no auditório do Superior Tribunal de Justiça entre os dias 26 a 28 de setembro de 2007. Portanto, qualquer levantamento realizado ou previsão estabelecida nesse componente de custo deve ser examinados atenciosamente, pois um cálculo efetuado erroneamente pode inviabilizar vários processos produtivos da empresa.

A recomendação aqui é a seguinte: no momento do estabelecimento das previsões estatísticas com base nas séries temporais de mão-de-obra, o gestor responsável pelo processo de implantação do modelo, deve estar atento e considerar itens imprescindíveis ao custo deste componente, tais como: Benefícios, Encargos Sociais (Vide tabela abaixo), Acordos Coletivos de Trabalho, Plano de Cargos e Salários, etc.

\begin{tabular}{|l|r|}
\hline \multicolumn{2}{|c|}{ GRUPO A } \\
\hline INSS Patronal & $20,00 \%$ \\
\hline FGTS & $8,00 \%$ \\
\hline SAT - Seguro Acidente de Trabalho & $2,00 \%$ \\
\hline 5 S's & $3,10 \%$ \\
\hline - SENAC / SENAI & $1,00 \%$ \\
\hline - SESC / SESI & $1,50 \%$ \\
\hline - SEBRAE & $0,60 \%$ \\
\hline INCRA & $0,20 \%$ \\
\hline Salário Educação & $2,50 \%$ \\
\hline TOTAL & $\mathbf{3 5 , 8 0} \%$ \\
\hline
\end{tabular}

\begin{tabular}{|l|r|}
\hline \multicolumn{2}{|c|}{ GRUPO B } \\
\hline $13^{\circ}$ Salário & $8,33 \%$ \\
\hline Férias & $8,33 \%$ \\
\hline Abono Férias & $2,78 \%$ \\
\hline Licença Prêmio & $1,67 \%$ \\
\hline TOTAL & $\mathbf{2 1 , 1 1 \%}$ \\
\hline
\end{tabular}

\begin{tabular}{|c|c|}
\hline \multicolumn{2}{|c|}{ GRUPO C } \\
\hline \multicolumn{2}{|c|}{ Inexistente } \\
\hline \multicolumn{2}{|c|}{ GRUPO D } \\
\hline (Grupo A * Grupo B) & $7,56 \%$ \\
\hline TOTAL & $7,56 \%$ \\
\hline
\end{tabular}


Os índices apresentados na tabela anterior irão sofrer variações de acordo com o tipo da empresa, portanto é necessária uma verificação prévia na legislação vigente.

Outro ponto importantíssimo a ser analisado em relação à mão-de-obra é a questão da identificação e a devida alocação dos custos destes recursos aos respectivos processos produtivos. Em empresas públicas prestadoras de serviços, estes custos, por ser de caráter público, trata-se de custos fixos e de difícil mobilidade, onde a complexidade das atividades dificulta o planejamento e o controle, onde esta complexidade tem vinculação ao fato do mesmo empregado desempenhar suas tarefas em atividades múltiplas (recurso compartilhado) provocando a necessidade de controle do tempo dedicado para o devido gerenciamento dos custos de produção (apontamento de hora trabalhada em cada atividade).

Percebe-se uma necessidade clara de um acompanhamento específico para os recursos de mãos-de-obra em empresas públicas prestadores de serviços, sejam eles vinculados às áreas de Tecnologia da Informação e Comunicação, Saúde, Jurídicas, etc. Esta é uma atribuição do gestor responsável pelo processo de implantação do sistema $A B C$.

A segunda consideração a ser apresentada é referente a alguns aspectos que são fundamentais na implantação do sistema de custeio baseado em atividade em empresas públicas prestadoras de serviços, tais como: apoio total da direção da empresa devido às dimensões no modelo, análise de custo/benefício das informações geradas pelo sistema, conscientização de que as informações precisam ser alimentadas pelos gestores de cada processo produtivo e que o modelo necessita constantemente ser avaliado e atualizado.

A terceira consideração a ser apresentada é a necessidade de ser ter sistemas de informação confiáveis, a nível estratégico, e integrados ao Sistema de Custos para o suporte na implantação do modelo e para uma boa gestão dos custos. Aqui vão alguns exemplos: Sistema de Recursos Humanos, Sistema de Controle Patrimonial, Sistema de Aquisições e Contratos, Sistema de Apropriação de Recursos, etc.

Segundo Abreu (1999, p.32), sistemas de informações estratégicos são:

Sistemas de Informações Estratégicos são aqueles que mudam os objetivos, produtos, serviços ou relações ambientais de uma empresa. Os sistemas que 
têm este efeito sobre uma organização literalmente mudam a maneira pela qual a empresa faz negócios. Neste nível, a tecnologia da informação leva a organização a novos padrões de comportamento, ao invés de simplesmente dar suporte e sustentação à estrutura existente, aos produtos existentes e/ou aos procedimentos de negócios existentes (ABREU, 1999, p.32)

\section{2 - Sistema de custeio e a previsão orçamentária}

Atualmente, uma vantagem gerada pela distribuição do orçamento é o fornecimento de um meio de transmissão dos planos da administração a toda a organização, pois, no momento das previsões orçamentárias, os gerentes são forçados a pensarem no futuro e como planeja-lo. Porém, o orçamento não traz uma visão clara de avaliação da sua execução, pois em suas previsões e distribuições o fator capacidade de produção não é considerado.

O gerenciamento de custos se preocupa efetivamente com a gestão de suas capacidades de produção (aspecto operacional), de modo que, antes de qualquer investimento é analisado primeiramente se o processo produtivo tem ou não disponibilidade de produção para depois verificar a real necessidade da despesa. No orçamento, esta vinculação com a capacidade de produção é apenas uma expectativa, uma meta desejável a ser alcançada. Portanto, se a distribuição orçamentária for constantemente derivada de uma análise gerencial de custos (mesmo que seja uma análise histórica), os recursos orçamentários serão executados com maior eficiência, pois no gerenciamento de custos a variável capacidade de produção é monitorada periodicamente o que gera uma vinculação rígida entre o investimento e o respectivo ganho de produtividade derivado deste investimento (despesa). 


\section{5 - CONCLUSÃO}

Dentre os objetivos estabelecidos no projeto e conforme proposto na formulação do problema de pesquisa, este trabalho apresentou os conceitos, as diretrizes e as considerações a respeito da implantação e gerenciamento do sistema de custeio baseado em atividades focado na utilização eficiente de recursos, na gestão empresarial estratégica, no gerenciamento dos custos de ociosidade, na eficiência alocativa e na geração de resultados.

O plano de ação da implantação e gerenciamento do sistema $A B C$ em empresas públicas prestadoras de serviços requer, conforme mencionado acima, diretrizes e considerações para o seu sucesso, a saber:

Diretrizes: conhecimento da estratégia empresarial a ser seguida (Competitiva ou Social), considerar aspectos gerenciais (Operacional, Tático e Estratégico), identificação dos processos produtivos da empresa com suas respectivas estruturas de custos e ter bem definida a cadeia de alocação dos custos (Recursos, Atividades e Objetos de Custos).

Considerações: estabelecer uma previsão de custos para o controle gerencial (Custo Padrão), atenção aos elevados custos de pessoal nas empresas públicas prestadoras de serviços, apoio empresarial ao nível de diretoria, comprometimento ao nível operacional e um sistema de informação adequado à metodologia.

Portanto, o trabalho apresentou, com o controle e gerenciamento dos custos, uma possibilidade de introduzir mecanismos de medição de eficiência no setor público, onde o Activity Based Costing ( $A B C$ ), por ser uma metodologia detalhada de apuração de custos, consegue apresentar resultados mais precisos, respondendo plenamente aos principais objetivos da organização. Um sistema de Custeio Baseado em Atividades bem definido e adaptado às estratégias, estruturas, capacidades e realidades empresariais, obtêm-se benefícios diversos como: um melhor desempenho organizacional, melhor nível de integração e de gerenciamento de processos de 
negócios, maior flexibilidade e agilidade para obtenção de informações gerenciais e melhores níveis de qualidade e segurança de informações corporativas. 


\section{REFERÊNCIAS}

ABREU, A. F. Sistemas de informações gerenciais: uma abordagem orientada a negócios. Florianópolis: IGPI, 1999.

ALBRECHT, Karl. Revolução nos serviços: como as empresas podem revolucionar a maneira de tratar os seus clientes. 4.ed. São Paulo: Pioneira, 2000.

ALONSO, M. Custos no serviço público. Revista do Serviço Público, Brasília, v 50, n. 1, p. 37-62, jan./mar. 1999.

BACIC, M. J. Escopo da gestão estratégica de custos em fase das noções de competitividade e de estratégia empresariais. In: 1ำ Congresso Brasileiro de Gestão Estratégica de Custos, 1994, Rio Grande do Sul. Anais...Rio Grande do Sul: UNISINOS, 1994. v.1. p. 295-304.

BERTS, K. e KOCK, S. Implementation considerations for activity-based cost systems in service firms: the unavoidable challenge. Management Decision, v. 33, n.6, p.57-63, 1995.

BORNIA, A. C. Análise Gerencial de Custos - Aplicação em Empresas Modernas. 2.ed. São de Paulo: Editora Atlas, 2009.

CANTO, A. TCO - Total Cost of OwnerShip. In: I Congresso de Administração de Informática, 1996, Curitiba.

Casas, A. L. Marketing de Varejo. 1.ed. São Paulo: Atlas, 1992.

COUTINHO, L.; FERRAZ, J. Estudo da Competitividade da Indústria Brasileira, SP, Editoras da UNICAMP e Papirus, 1994.

FAMA, R., HABID, C.V.S. Implantação do sistema de custeio ABC em empresas prestadora de serviços de saúde - vantagens e limitações. In: VI Congresso Brasileiro de Custos, 1999, São Paulo. Anais. São Paulo, FEA/USP,1999.

FERGUSON, C. E. Microeconomia. 9.ed. Rio de Janeiro: Forense-universitária, 1986. 
FERREIRA, A. B. H. Novo Dicionário da Língua Portuguesa. Rio de Janeiro: Nova Fronteira, 1975.

FRANCIA, A. J. et al. PORTER, M. C.; STRAWSER, R. H.; STRAWSER, J. R. Managerial accounting.,9. ed. Houston: Dame, 1992. p. 4.

Garrison, R. H.; Noreen, E. W. Contabilidade Gerencial. 9. ed. Rio de Janeiro: LTC Editora, 2001.

GASPARETTO, Valdirene. Uma discussão sobre a seleção de direcionadores de custo na implantação do custeio baseado em atividades. Florianópolis: UFSC. 1999. Dissertação (Mestrado de Engenharia da Produção).

GOLDENBERG, M. A arte de pesquisar: como fazer pesquisa qualitativa em Ciências Sociais. 4.ed. Rio de Janeiro: Record, 2000.

HORNGREN, C. T. et al. Foster, G.; Datar, S. M. A. Contabilidade de Custos, 9. ed. Rio de Janeiro: LTC, 1997.

IOB, Boletim de Contabilidade. Contabilidade de Custos - A contabilidade de custos nas empresas de prestação de serviços, f. 34, n. 1 e 2, 2006.

IBGE - Instituto Brasileiro de Geografia e Estatística, 2008. Sistema IBGE de recuperação automática - SIDRA, disponível em: http://www.sidra.ibge.gov.br/

KAPLAN, R. S. et al. Young, S. M.; Banker, R. D.; Atkinson, A. A. Contabilidade Gerencial, 2. ed. São Paulo: Atlas, 2000. Capitulo 1, p. 33-68. Capitulo 2, p. 293-327.

KAPLAN, R. S.; COOPER, R. Custo e Desempenho - Administre seus custos para ser mais competitivo. 1.ed. São Paulo: Futura, 1998.

LAWRENCE, W. B. Contabilidade de Custos. 5.ed. São Paulo: Ibrasa, 1977.

NAKAGAWA, M. ABC - Custeio Baseado em Atividades. 1. ed. São Paulo: Atlas, 1994. 
NEVES, S.; VICECONTI, P. Contabilidade de Custos - Um enfoque direto e objetivo, 6 ed, São Paulo: Frase, 2000. Capítulo 2, p. 5-9.

PADOVEZE, C. L. Contabilidade Gerencial: Um enfoque em sistema de informação contábil. 4. ed, São Paulo: Atlas, 2004.

PENHA, E. M.; LIRA, C.J. A. Projeto conceitual do sistema de custos ABC: análise e decisão em uma empresa de serviços bancários. XV Encontro Nacional de Engenharia de Produção. Anais. 1999.

PEREZ, J. H. J.; OLIVEIRA, L. M. Contabilidade de custos para não contadores. São Paulo: Atlas, 2000.

SHINGO, Shigeo. Study of Toyota production system from industrial engineering viewpoint. Tokyo: Japan Management Association,1981.

SILVA, E. L.; MENEZES, E. M. Metodologia da Pesquisa e Elaboração de Dissertação. In: 3.ed. Florianópolis: UFSC, 2001. Capítulo 3, p. 19-23.

TACHIBANA, W. K. ; FILHO, E. E.; SANTOS F. C. A. Administração Estratégica de Custos. In: 1ํㅡ Congresso Brasileiro de Gestão Estratégica de Custos, 1995, São Leopoldo - RS.

VERGARA, S.C. Começando a definir a metodologia. In: Projetos e relatórios de pesquisa em Administração. 3.ed. São Paulo: Atlas, 2000. Capítulo 4, p. 46-53. 
ANEXO A - Valores a preços correntes e a preço de mercado

Brasil - Milhões de Reais

\begin{tabular}{|c|c|c|c|c|}
\hline \multirow{2}{*}{ SETORES E SUBSETORES } & \multirow{2}{*}{$\begin{array}{c}2007 \\
\text { OUT-DEZ }\end{array}$} & \multicolumn{3}{|c|}{2008} \\
\hline & & JAN-MAR & ABR-JUN & JUL-SET \\
\hline Agropecuária - total & 27.499 & 43.745 & 53.688 & 37.330 \\
\hline Indústria - total & 161.845 & 150.442 & 168.483 & 189.255 \\
\hline Extrativa mineral & 14.696 & 14.626 & 19.248 & 26.227 \\
\hline Transformação & 97.904 & 88.391 & 98.936 & 109.947 \\
\hline Construção civil & 28.902 & 28.106 & 30.714 & 33.958 \\
\hline Produção e distribuição de eletricidade, gás e água & 20.343 & 19.319 & 19.585 & $\overline{19.122}$ \\
\hline Serviços - total & 395.373 & 367.404 & 398.261 & 404.973 \\
\hline Comércio & 69.781 & 67.131 & 74.263 & 80.346 \\
\hline Transporte, armazenagem e correio & 32.510 & 30.845 & 32.909 & 35.203 \\
\hline Serviços de informação & 21.391 & 20.548 & 20.820 & 22.195 \\
\hline Intermediação financeira, seguros, previdência complementar e serviços relativos & 43.848 & 43.884 & 45.667 & 37.682 \\
\hline Outros serviços & 84.223 & 71.208 & 84.088 & 87.870 \\
\hline Atividades imobiliárias e aluguel & 49.915 & 50.809 & 52.149 & 53.460 \\
\hline Administração, saúde e educação públicas & 93.705 & 82.978 & 88.366 & 88.216 \\
\hline Valor adicionado a preços básicos & 584.716 & 561.591 & 620.433 & 631.558 \\
\hline Impostos líquidos sobre produtos & 102.026 & 104.052 & 109.154 & 115.779 \\
\hline PIB a preços de mercado & 686.742 & 665.643 & 729.586 & 747.337 \\
\hline Despesa de consumo das famílias & 415.065 & 417.705 & 435.725 & 452.164 \\
\hline Despesa de consumo da administração pública & 154.027 & 129.341 & 138.691 & 138.004 \\
\hline Formação bruta de capital fixo & 121.110 & 122.801 & 134.961 & 152.589 \\
\hline Variação de estoque & -10.259 & -416 & 18.111 & 748 \\
\hline Exportação de bens e serviços & 90.290 & 79.166 & 96.883 & 113.664 \\
\hline Importação de bens e serviços (-) & 83.490 & 82.954 & 94.784 & 109.832 \\
\hline
\end{tabular}

Fonte: Sistema do IBGE de recuperação automática - SIDRA

IBGE - http://www.sidra.ibge.gov.br/ 
ANEXO B - Valores a preços correntes (2005 - 2008)

Brasil - Milhões de Reais

\begin{tabular}{|c|c|c|c|c|c|c|c|}
\hline \multirow{2}{*}{ ANO } & \multirow{2}{*}{ TRIMESTRE } & \multirow{2}{*}{ AGROPECUÁRIA } & \multirow{2}{*}{ INDÚSTRIA } & \multirow{2}{*}{ SERVIÇOS } & \multirow{2}{*}{ PIB pc * } & IMPOSTOS SOBRE & \multirow{2}{*}{ PIB pm ** } \\
\hline & & & & & & SERVIÇOS & \\
\hline \multirow{4}{*}{2005} & $\mathbf{I}$ & 25771 & 122631 & 275896 & 424298 & 72643 & 496941 \\
\hline & II & 31672 & 136373 & 292224 & 460269 & 74581 & 534850 \\
\hline & III & 25971 & 138718 & 300463 & 465153 & 76408 & 541560 \\
\hline & IV & 21749 & 141560 & 329224 & 492532 & 81355 & 573887 \\
\hline 2005 & & 105163 & 539283 & 1197807 & 1842253 & 304986 & 2147239 \\
\hline \multirow{4}{*}{2006} & $\mathbf{I}$ & 26516 & 129069 & 311971 & 467556 & 79251 & 546807 \\
\hline & II & 30506 & 144825 & 325815 & 501146 & 79892 & 581037 \\
\hline & III & 28825 & 155552 & 336188 & 520565 & 83613 & 604177 \\
\hline & IV & 25382 & 156157 & 363929 & 545468 & 92308 & 637776 \\
\hline 2006 & & 111229 & 585602 & 1337903 & 2034734 & 335063 & 2369797 \\
\hline \multirow{4}{*}{2007} & $\mathbf{I}$ & 33160 & 141980 & 346681 & 521821 & 86322 & 608143 \\
\hline & II & 40588 & 155352 & 361319 & 557258 & 90175 & 647434 \\
\hline & III & 31769 & 164544 & 363411 & 559724 & 95569 & 655292 \\
\hline & IV & 27499 & 161845 & 395373 & 584716 & 102026 & 686742 \\
\hline 2007 & & 133015 & 623721 & 1466783 & 2223519 & 374092 & 2597611 \\
\hline \multirow{3}{*}{2008} & $\mathbf{I}$ & 43745 & 150442 & 367404 & 561591 & 104052 & 665643 \\
\hline & II & 53688 & 168483 & 398261 & 620433 & 109154 & 729586 \\
\hline & III & 37330 & 189255 & 404973 & 631558 & 115779 & 747337 \\
\hline
\end{tabular}

Fonte: Sistema do IBGE de recuperação automática - SIDRA

IBGE - http://www.sidra.ibge.gov.br/ 